Publications 2015, 3, 43-64; doi:10.3390/publications3020043

Article

\title{
English Writing for International Publication in the Age of Globalization: Practices and Perceptions of Mainland Chinese Academics in the Humanities and Social Sciences
}

\author{
Meng Ge \\ Faculty of Education, University of Hong Kong, Pokfulam Road, Hong Kong, China; E-Mail: gmhku@hku.hk; \\ Tel.: $+852-2241-5422$ \\ External Editor: Yongyan Li \\ Received: 25 January 2015 / Accepted: 18 March 2015 / Published: 25 March 2015
}

\begin{abstract}
Much scholarly attention has been given to the English writing and publishing practices of the academics in non-Anglophone countries, but studies on such practices in the humanities and social sciences (HSS) have in general been limited. The case of Mainland Chinese HSS academics is potentially interesting. On the one hand, international publications in these disciplines have been on the increase, which are also encouraged by the national research policy of "going-out". On the other hand, unlike those in science and technology (S\&T), such practices in the HSS are still much less institutionalized at the local level. In the study reported in this article, semi-structured interviews were conducted with nine academics in economics, sociology and archaeology from the Chinese Academy of Social Sciences (CASS), and all nine participants had prior experience in international publishing. With a focus on participants' experiences and perceptions, findings from this study demonstrated the relatively passive role participants played in their international publications, the importance of various resources in bringing forth these publications, and the relations between participants' alignments with the local or international community and their voluntary investment in participating in their practices. Implications of the study were also discussed.
\end{abstract}

Keywords: International publication; Humanities and social sciences; Mainland Chinese academics; Internationally-indexed journals; English academic writing 


\section{Introduction}

With the rise of English as the hegemonic language of scientific communication [1,2] and the dominance of "center" standards of quality and value in academic research [3,4], English writing for publication in internationally-indexed journals (e.g., Science Citation Index or SCI; Engineering Index or EI; Index to Scientific \& Technical Proceedings or ISTP) has generally been accepted as the norm in science and technology (S\&T). Strenuous effort has been observed to have been made by nonnative English-speaking (NNES) academics in the "periphery" to bid for publication in oftentimes "center"based English-medium journals [5-7]. Compared with S\&T, English writing for international publication in the humanities and social sciences (HSS) has been acknowledged as more complex and less institutionalized. Nevertheless, recent years have also witnessed its increase and the mounting importance accorded to "center"-based indexes in the HSS (e.g., Social Science Citation Index or SSCI; Arts \& Humanities Citation Index or A\&HCI), for instance, in Europe, Hong Kong, and Taiwan $[4,8,9]$. On the one hand, such practices are in line with government authorities' determination to enhance the competitiveness and visibility of universities in the global ranking system through boosting their research performance. On the other hand, the justifiability of employing these indexes in the evaluation of HSS research has become a focus of debate, and the challenging nature of writing and publishing in indexed journals a source of conflicts and resistance, especially for researchers from non-Anglophone countries [9-11]. In this interview-based study, I explored these issues in the context of Mainland China, where similar trends in the HSS have been developing, but not yet to the extent as in the regions abovementioned. It was expected that the study could expand our understanding of these issues and inform the practices of institutional administrators and HSS researchers.

In Mainland China, historically, a sole emphasis had been laid on S\&T in national research policies. Since around the 1980s, S\&T research has been encouraged to "connect tracks" with Western countries, and the "center"-based index SCI has been adopted by many universities and research institutions as an assessment indicator. Both facts have facilitated the Anglicization of S\&T in China [12]. As a result, the ranking of Mainland China in SCI rose from eighth to second between 2001 and 2012, with more than 190,000 articles published in SCI journals by Chinese scientists in 2012 [13].

The fast development of the HSS in Mainland China, especially its Anglicization, by contrast, is a more recent phenomenon. Between 1956 and 2006, there were altogether only 9951 articles from Mainland Chinese academics that had been indexed by SSCI and A\&HCI [14], whereas in 2012, SSCI alone indexed 8012 articles from Mainland Chinese HSS researchers, whose productivity ranked eighth worldwide [13]. As shown by these figures, despite the overall small number when compared to S\&T, the growth in the international publication in the HSS was exponential.

As the background of this development, at least two major forces can be observed: the increasing exchanges of Chinese academia with international academia in the age of globalization; and the policies at all levels that encourage English writing and publishing in the HSS. According to Steger [15], globalization is characterized by the intensifying of "worldwide social interdependencies and exchanges" and people's "growing awareness of deepening connections between the local and the distant" [15] (p. 13). In the realm of academic research, globalization has been keenly felt in at least three aspects. Firstly, surging numbers of academics have started their career from studying in 
overseas universities, and have thus been exposed to and/or acculturated into the values and practices of these communities [16]. Secondly, extensive cross-border exchanges and collaboration have become the inspiration and sources of knowledge production for increasing numbers of scholars [17]. Thirdly, the accelerated flow of talent and knowledge, the constant encounters of the local and the global as well as the continual blurring of boundaries between nation states and academic communities have brought about both opportunities and tensions for academics worldwide [18].

In line with the globalizing trends, the strengthening of national power and the increasingly important role China plays in the world, the focus of national research policies have also been broadened from including S\&T alone to encompassing HSS as well; an "import" orientation replaced by an "import-export" one, where the "going-out" of HSS research is explicitly advocated [12]. As part of the conscious effort made to boost China's discourse power on the world stage, "going-out", originally a strategy in the economic realm promulgated by the central government in 2001 [19], has become a catchword in academia, especially in the HSS disciplines. In the implementation and promotion of the "going-out" of HSS disciplines, English writing and publishing is often viewed as one of the primary means, which has attracted much scholarly attention from researchers in different areas.

Most noticeably, researchers in library and information science have adopted various quantitative methods to analyze aspects of the data retrieved from SSCI, A\&HCI and other citation databases so as to learn of the presence made by Chinese researchers in them and its features. Following an analysis of the diachronic changes in the contributions made by Mainland Chinese academics to SSCI and A\&HCI between 1956 and 2006 [14], He [20,21] analyzed the distribution of such output across different disciplinary areas and the productivity of different institutions around the country during the same time period. Using the two databases, both Li and Hua [17] and Zheng [22] examined the collaboration patterns of Mainland Chinese HSS researchers with their domestic and overseas counterparts. The academic impact of individual disciplines, researchers and articles, among others, was also analyzed.

Other than this rich body of quantitative work, a small number of qualitative studies were also carried out by writing researchers to investigate the attitudes and practices of individual HSS academics in relation to their English writing and publishing. Different from the broad trends and patterns identified by information scientists, this line of research has provided finer descriptions of and deeper insights into the ideological, practical and political factors involved in the Anglicization of the HSS disciplines.

Flowerdew and Li [11] examined the use of English and the attitudes towards the official policy encouraging English-medium international publications among 20 HSS academics from a research-oriented Mainland Chinese university. Seven out of the 20 participants had prior experience in English publishing. It was found that although nearly all participants attached considerable importance to English, their written output was very limited. The participants with stronger aspiration to produce English writing tended to be more optimistic about overcoming the potential linguistic barrier. Strong resistance was expressed by participants towards the official policy encouraging international publications on the ground of a range of concerns, including the unfavorable assessment systems and the justifiability of applying the criteria of S\&T to HSS, among others. 
In face of the changing national research policy, Feng, Beckett and Huang [12] interviewed journal editors, directors of scientific research administration in higher education institutions and researchers from both S\&T and HSS to learn about their current practices regarding research writing and publishing as well as their perceptions of the "going-out" policy. All six researchers, despite their different practices and perceptions, acknowledged the ever-increasing influence from the specialist literature in English on the knowledge structure of the academic research in Chinese. Regarding the "going-out" policy, concerns were expressed as for how it might be implemented without sacrificing the academic independence of China's HSS research.

Jiang [23] focused on the difficulties encountered by younger HSS researchers in their attempt to publish English articles in international journals and the coping strategies they adopted. Interviews were conducted with 22 young researchers from a range of HSS disciplines based in one top-ranking university in Mainland China. Twelve out of the 22 participants had prior experience in English publishing. Institutional policies and overseas educational background were reported to be the primary stimuli behind such practices. The different research paradigms between Chinese and Western academia were reported by those who had not written and published internationally as the major deterring factor. Language and communication were viewed as the main obstacles when writing and bidding for publication in English.

The abovementioned studies have found, in general, great divergences in the practices and perceptions of individual academics from different disciplinary, educational and institutional backgrounds. However, not enough attention has been paid to the practices and perceptions of those researchers who have actually published in international journals. If, as reported by Flowerdew and $\mathrm{Li}$ [11], there is strong resistance towards the policy of encouraging international publications among HSS researchers, how did some of them start to write and publish internationally, and under what circumstances did they write these articles? Besides, with all the (potential) difficulties and concerns English writing and publishing involves [12,23], what kinds of attitudes have some researchers developed through their own practices and how these attitudes might influence their future practices? If the national research policy aims at promoting international publications and the "going-out" of HSS research, answers to these questions would be valuable sources of information for the formulation and implementation of micro-level policies that guide local practices. Furthermore, previous studies have mostly been carried out in higher education context. Another major force in the production of HSS scholarship, academic research institutes such as the academies of social sciences at different levels, has been largely ignored. In view of the gaps indicated above, it is meaningful to expand the small existing research base by conducting another study focusing on HSS academics that have had the experience in international publishing.

\section{Methods}

\subsection{Research Questions}

Set in the general background reported and research literature reviewed, this study aimed to probe further into the issue of English writing and publishing among HSS academics in Mainland China. Specifically, this study was designed to answer the following research questions: 
1) What are the initial experiences of the participants' writing and publishing in internationally-indexed journals like, and under what circumstances did they write their internationally-indexed articles?

2) What attitudes do the participants hold towards writing and publishing in internationally-indexed journals?

"Internationally-indexed" journals or articles, as in this study, refer to those indexed by SSCI and A\&HCI. Although, as confirmed later in the interviews, seven out of the nine research participants have also published in English in the forms of book chapters, research articles (in journals other than SSCI or A\&HCI ones), conference proceedings, etc., the sources vary greatly, and not all participants could provide a list of these works. For the sake of objectivity and consistency, and considering the general high quality of the two indexes, only SSCI and A\&HCI journals and articles were counted in this study.

\subsection{Research Site}

The Chinese Academy of Social Sciences (CASS) was chosen as the site for this study. As "the highest academic research institution in the fields of philosophy and the social sciences" and "a national centre for comprehensive studies" [24] (p. 41) in China, the CASS boasts more than 30 research institutes specializing in different areas within the HSS. Being affiliated to the State Council, it has more authority both administratively and academically over many other research institutes of the country, often serving as the "leader" and a "model" within an area. Moreover, its central status also means abundant resources and more privileges in conducting research, organizing exchanges and initiating collaborations. Considering these facts, the perceptions and practices of its members, some of whom have participated in the formulation of national research policies and relevant documents themselves, are crucial reference point to the understanding of the Anglicization of the HSS in the country.

At the time when this study was conducted, unlike some higher education institutions, English publications were not a prerequisite for employment at the CASS, nor were there any stimulus measures to forcefully encourage English publications [25]. While selecting "Outstanding Research of the Year", a regular award granted at the CASS, publications in all languages were viewed as equal. Nevertheless, under the guidelines enacted by the academic committee at the CASS level, each research unit was entitled to draw out its own assessment and rewarding schemes based on their own specific circumstances.

In the three CASS research institutes involved in this study, namely, sociology, economics, and archaeology (the selection of the three institutes/disciplines will be discussed in Section 2.3), international publications were treated differently. Considerable weight was given to such publications in sociology and economics, but not in archaeology [25]. In sociology, drawing on the Chinese journal index of CSSCI developed by Nanjing University, domestic Chinese journals were put into three categories and assigned 5 (top-ranking key journals), 3 (other key journals indexed by the CSSCI) or 2 points (journals outside of the index); English-medium journals indexed by the SSCI were viewed as equivalent to the top-ranking key Chinese journals and assigned 5 points as well. In annual assessment, a common practice adopted by many Chinese academic institutions to evaluate the performance of 
researchers, the academic output of a researcher was calculated within such a point system $[11,26]$. However, the institute also realized the limitations of such practices on the ground that publication outlets cannot be equated to quality in a simplistic manner, and an academic board was therefore organized to assess the quality and value of research, especially when there was disagreement or dispute. In economics, similar practices were adopted. In annual assessment, the academic output of a researcher was calculated with both the word count of a publication and the weight factor of the journal being taken into consideration. English-medium international journals were usually assigned a weight factor between 3 and 4, equivalent to that of top-ranking Chinese journals. In archaeology, normally no differing value was accorded to the articles published in different journals, either in English, Chinese or other languages. It was only when a researcher applied for the highest academic rank of (associate) research fellow that publications in the three top Chinese journals in the discipline became a prerequisite.

\subsection{Data Collection and Data Analysis}

To locate potential participants for this study, the full name of the CASS was used as the keyword to search the online databases of SSCI and A\&HCI operated by Thomson Reuters. The 550-odd articles yielded (between 1980 and 2013) were categorized according to their authors, and less than 40 academics that had published at least three articles (regardless of their ranking in the author list and the time span their publications covered considering the overall small number of articles) were identified. Fifteen researchers from the institutes/disciplines of economics, sociology and archaeology were invited for an interview with me through three contact persons. The three institutes/disciplines were selected as the representatives of the seven most productive disciplinary areas in terms of their internationally-indexed publications at the CASS between 1956 and 2006 - they ranked first, fourth and seventh, respectively [21].

Nine of the 15 researchers invited gave their consent and met me in their offices in June and August 2013 for a semi-structured interview lasting between 40 and 90 minutes (the basic information regarding the participants can be found in Table 1 below). With the permission of the participants, all the interviews were audio recorded for later transcription and analysis. To elicit information from the participants, a list of questions was formulated and used in the semi-structured interviews. As Prior [27] (p. 188) put it, "semi-structured interviews move between scripted questions and open-ended conversations". These questions were thus used flexibly so that emerging issues could be followed upon:

1) How did you start to write for and publish in internationally-indexed journals?

2) Why/Under what circumstances did you write your internationally-indexed articles?

3) What do you think are the benefits and drawbacks of writing these articles and publishing in these journals?

4) What are the most challenging things for you in the writing and publishing processes? How do you usually handle them?

5) How do you usually make the decisions of using English or Chinese and of publishing in domestic or international journals before you start to write an article? 
6) How do you view the importance of publishing in international journals for your academic career?

7) How do you feel about the trends of "globalization" and "Anglicization" in academia, especially in your discipline?

8) How are internationally-indexed publications received in your institute at the policy level? What do you think of these policies?

9) What are your future plans in terms of English writing and international publication? Why?

10) Is there anything I did not ask but you feel strongly about?

Table 1. Basic information of the interview participants.

\begin{tabular}{cccccccc}
\hline Code & Gender & $\begin{array}{c}\text { Age } \\
\text { group }\end{array}$ & PhD (Where \& when) & Academic rank & Discipline & $\begin{array}{c}\text { No. of SSCI and } \\
\text { A\&HCI articles } \\
\text { (Time span) }\end{array}$ & $\begin{array}{c}\text { Annual } \\
\text { output } \\
\text { (Average) }\end{array}$ \\
\hline ECO1 & M & $36-40$ & Mainland China, 2003 & Research fellow & Economics & $5(2010-2011)$ & 2.5 \\
ECO2 & F & $36-40$ & Mainland China, 2006 & Research fellow & Economics & $9(2006-2013)$ & 1.13 \\
ECO3 & M & $56-60$ & Mainland China, 1989 & Research fellow & Economics & $18(1998-2013)$ & 1.13 \\
SOC1 & F & $56-60$ & Mainland China, 1998 & Research fellow & Sociology & $4(2007-2013)$ & 0.57 \\
SOC2 & F & $36-40$ & Mainland China & Assistant & Sociology & $3(2008-2012)$ & 0.6 \\
SOC3 & M & $31-35$ & Mainland China, 2010 & Assistant & Sociology & $3(2012-2013)$ \\
ARCH1 & M & $56-60$ & US, 1996 & Research fellow & Archaeology & $7(1999-2013)$ & 0.47 \\
ARCH2 & M & $61-65$ & Japan, 1993 & Research fellow & Archaeology & $11(1998-2012)$ & 0.73 \\
ARCH3 & M & $46-50$ & Mainland China, 1991 & Research fellow & Archaeology & $10(2002-2013)$ & 0.83 \\
\hline
\end{tabular}

As shown in Table 1, until the time of this study, the nine participants had published 70 SSCI and A\&HCI articles with their affiliation being the CASS. Only 10 of the articles have one of the participants as the sole author, and the other 60 are all joint publications involving 2 to 33 authors. Among the 60 collaborative works, 20 have one of the participants as their first author, 10 as the second author, and in the other 30, the participants rank the third or even further behind in the author list; 32 have overseas academics as the first author, and the other 8 have academics from the CASS or other domestic institutions as the first author. Moreover, although all participants are viewed as "prolific" in internationally-indexed publications when compared with their peers at the CASS and some other domestic institutions, the number of such publications by individual participants ranges from 3 to 18 only. If the length of time taken to accumulate these publications is considered, the annual productivity is even lower (from 0.47 to 2.5 articles). These figures seem to indicate the overall marginal position of English research writing in the academic life of the participants.

In analyzing the data, I transcribed all interviews totaling 618 minutes verbatim. After breaking them down into segments, I coded the data through open coding and analytical coding [28]. As Merriam [28] (p. 178) put it, coding is a "process of making notations next to bits of data that strike you as potentially relevant for answering your research questions". For open coding, I identified "any segment of data that might be useful" to answer the two research questions stated earlier, and assigned 
them codes using the participant's words, my words or concepts from the literature; for analytical coding, I combined the descriptive codes into more abstract and condensed "categories" [28] (pp. 178-180). Then, I put all relating evidence in the data into these categories through repeated reading. These categories and evidence were used to answer the two research questions.

Considering that the number of participants is small, and they are from a limited range of HSS disciplines and a single institution only, the findings from this study shall not be used to make strong generalizations. Rather, it was expected that the presentation of individual participants' experiences and viewpoints, oftentimes conflicting or divergent, could be used to enrich and broaden our understanding and to explore issues related to English-medium international publication in the HSS in non-Anglophone countries.

\subsection{Ethical Concerns}

In the process of data collection, I followed the principle of "informed consent" [29]. Consent form was signed with each participant before interviews were carried out and audio recorded. I made sure participants understood the purpose of the research and how the data were to be used. According to Yin [30] (p. 181), anonymity in case studies exists at two levels: the entire case and the individual persons within the case; it is desirable to disclose the identities of both, yet realistic constraints justify anonymizing one or both. In this study, the uniqueness of the site necessitated identifying it. On another front, anonymity of individual participants must be protected "unless they give direct permission to the contrary" [29] (p. 63). With some participants unwilling to be identified in the research and others being neutral, I anonymized all participants and assigned them codes as marked in Table 1.

\section{Research findings}

\subsection{Research Question 1: What Are the Initial Experiences of the Participants' Writing and} Publishing in Internationally-Indexed Journals Like and under What Circumstances Did They Write Their Internationally-Indexed Articles?

As the following findings will show, the participants started to write and publish in international journals at different points of their career lives. From their accounts, three major "patterns" can be identified, although the distinction between them is not always clear-cut. After these initial experiences, most participants have continued to produce more of such articles.

\subsubsection{Native English-Speaking Collaborators as Mentors that Initiated and Guided the Endeavors}

When approached with this question, three younger participants (ECO1, ECO2 and SOC2) who obtained all their academic degrees in Mainland China mentioned their native English-speaking (NES) collaborators as mentors that had inducted them into the English discourse community. In all three cases, the participants have collaborators senior to them both in age and research experience. ECO1 started writing English articles while working as a post-doctoral researcher at an Australian university. The possibility of collaboration was first raised by his supervisor. With ECO1's positive reply, the two jointly wrote and published five SSCI articles. After returning to the CASS, ECO1 has largely stopped 
publishing English articles unless required by the funding bodies of his research projects because "it involves too much time and effort".

ECO2 met her American collaborator while attending a conference in the US. A congenial discussion at the conference venue led to her first SSCI publication first-authored by the American scholar. They continued to collaborate on another two SSCI articles and several book chapters. Building on that experience, ECO2 has both collaborated with her colleagues and worked alone to write English articles; either at the invitation of journal editors or her collaborators from the same institute (ECO3 being the most important one, who is another mentor figure for her). During the years, ECO2 has published a number of English articles on "worthy" and "meaningful" topics.

SOC2 got to know her Australian collaborator when the latter was working temporarily at the CASS as a visiting fellow. By proposing and co-authoring an article with SOC2, SOC2's collaborator not only familiarized her with English writing, but also triggered her interest in exploring deeper and further in the particular area they had probed into. SOC2 has thereafter published a second article with the same collaborator, which was initiated by SOC2; and another one with two different collaborators, at the suggestion of one of them when SOC2 was visiting Hong Kong. At the time when we met, SOC2 was working on yet another English article with a Swedish scholar.

\subsubsection{A Practice and/or Propensity Cultivated Through Extensive Overseas Experience}

Another three participants (SOC3, ARCH1 and ARCH2) related their English writing to their extensive overseas experience, particularly the formal education they received overseas. Through such experience, they were trained in the skills necessary for writing academically in English, engaged in English writing and publishing practices, and acculturated into the values and norms underlying such practices. ARCH1, a senior and renowned researcher in his area, was exposed to English academic writing when studying in the US. Publishing articles was a prerequisite for granting degrees then. Well aware of their weight, he published four articles either as the sole author or in collaboration with his supervisors. Upon his return to China and entry into the CASS, he is no longer under the pressure to publish in English, but with the invitations from journal editors, and when there are opportunities to publish in prestigious journals, he will still compose English articles. Besides, by being a member of various research teams, a typical work mode in archaeology, his name might be included in the author list of an article without his actually writing it.

$\mathrm{ARCH} 2$, another senior academic well-known in his field, obtained his PhD degree in Japan with Japanese as the language of instruction. His English is sufficiently good, but not up to the level of writing academically. The very experience in Japan made him realize the limitations of Japanese in learning first-hand knowledge in his field (often produced in English) and in disseminating his research to a larger audience. Therefore, he has been actively seeking researchers proficient in both English and Chinese to collaborate with him so they could also work as his translators. At least four of his articles were written this way. Just like ARCH1, his name could also be included in the author list of an article because he was in the research team behind it.

SOC3, the youngest participant, has successfully published three SSCI articles as the sole author. He was exposed to and trained in English writing while in the US as an exchange $\mathrm{PhD}$ student first and then in another American university as a post-doctoral researcher. The first of the articles was based on 
a writing sample for his exchange application. "To make full use of it", he modified it and submitted it to a secondary SSCI journal, and it was a success. The other two articles were written anew. Viewing English writing and international publication as "the general trend" and "important for personal development", SOC3 has initiated and managed all the writing, submission and revision by himself, although support from other sources has also been enlisted.

\subsubsection{High-Quality Research Attracts Collaborators or Opportunities for Publishing}

The last three participants (ECO3, SOC1 and $\mathrm{ARCH} 3$ ), all well-established researchers that were domestically-trained, have somewhat different experiences pertaining to the issue under discussion. Nonetheless, their collaborators and publishing opportunities seem to have been attracted to them by their high-quality research more than anything else. SOC1, who reported a strenuous effort to learn English but with unsatisfactory results, did not publish her first English article until 2007. After giving a presentation at a conference in the US, she was approached by a Chinese American scholar who expressed interest in co-authoring an article with her. Most of their discussion leading to the publication of the article was conducted in Chinese, and SOC1's contribution to the article in the sense of English writing was minimal. Different collaboration modes were adopted in her other three SSCI articles, and both domestic and overseas collaborators were involved in their writing, but SOC1 took a leading role in only one of them and language input from her remained limited.

Both ECO3 and ARCH3 started using English through reading specialist literature or writing and submitting English papers to international conferences at an early stage of their career. Their writing skills were developed in practice over time. ECO3, an economist with international reputation, has published the most SSCI articles among all participants. Viewed by his colleagues as an "exceptionally gifted language learner" well-versed in both oral and written English, ECO3, however, has never taken the initiative to submit to international journals. Seeing himself mainly as a researcher for domestic audience, he would write in English, either solely or collaboratively with his colleagues, only when invited by editors and friends. Besides, all his English publications are loosely based on the research previously released in Chinese as its "byproducts" for "the overseas scholars who are interested in Chinese economy but cannot read Chinese".

According to $\mathrm{ARCH} 3$, the $10 \mathrm{SSCI}$ articles with his name in the author list were not composed by him; but he has commented on or revised many of them. Being engaged in international collaboration with a Chinese American archaeologist for nearly two decades, they have had a large number of joint publications, both in English and Chinese. The SSCI-indexed ones were mostly written by his collaborator or other members of the team. ARCH3 has a good command of English and has published a book (jointly with his collaborator) and a number of non-SSCI articles and book chapters in English, but just like ECO3, he prefers using Chinese and has been writing less and less in English. Seeing himself as a member of the local community, ARCH3 does not care about making an impact in Western academia. 


\subsection{Research Question 2: What Attitudes Do the Participants Hold Towards Writing and Publishing in Internationally-Indexed Journals?}

Mixed attitudes were expressed by most participants regarding this question. Through their own experiences, the participants have perceived and recognized the merits and value of international journals and the benefits from publishing there. In the meanwhile, several issues that have restricted such practices as well as conflicting viewpoints on these issues were observed from the accounts of the participants.

\subsubsection{The Benefits of Publishing in English-Medium International Journals}

On the positive side, the participants listed the high visibility, rigorous standard, and diversified orientations of international journals as some of their most desirable characteristics. Accordingly, the process of writing and submitting to these journals was viewed as a learning process.

Firstly, ECO2, SOC2 and ARCH2 all emphasized that English journals could reach and appeal to a wider audience. The high visibility of these journals makes them ideal venues to disseminate their interesting and meaningful research, to both promote the work of Chinese researchers as a whole and to boost individual researchers for more attention and opportunities. As stated by ECO2,

Some well-researched issues in China cannot reach the international audience because of the language barrier. Even if you have written ten Chinese articles dealing with that same issue, it is very likely that the overseas academics still know nothing about it; with only one English article, that purpose can be served. For instance, after I published my 2007 (English) article, many overseas academics and organizations approached me, telling me they had read the article and found it interesting, and asking about the possibility of exchanges or collaboration. (ECO2)

SOC2 also mentioned that in her area, China's voices are rarely heard in the heated discussion in the international academic communities. She compared English journals to "megaphones" that help amplify the voices of Chinese researchers, about which increasing numbers of overseas academics are curious.

Similarly, ARCH2 made the following comments passionately,

We write and publish in English for the purpose of "going-out". For example, ancient Chinese history enriched by our archaeological evidence is much more vivid and charming than traditional historical records. It deserves international attention. Westerners might say they cannot understand Chinese. Now I am helping them with that (by writing and publishing our research in English-medium international journals). (ARCH2)

This aspect of international journals is similar to what Li and Flowerdew [8] observed from among a group of Hong Kong HSS academics, who reported "to reach a wide readership" (p. 284) as one of the motivations for their English writing and publishing. What is different in the case of the three academics above seems to be a strong sense of mission. Apart from their own self-realization and career development, the three participants all associated the high visibility of international journals with the promotion of the voices and accomplishments of Chinese scholars, whether the slogan of "going-out" was mentioned explicitly or not. 
Secondly, for ECO1, ARCH1 and ARCH2, internationally-indexed journals often, though not always, stand for high quality and rigorous academic standards, and those are some of the things they aspire to. In the case of ECO1, publishing in SSCI journals (rather than the non-indexed ones) seems to be a natural choice,

The moment we started to plan an article, we aimed at SSCI journals; otherwise, why bother? There were a few other journals inviting articles from us too, but they were not indexed by the SSCI, so we refused - we had concerns over their quality and impact. (ECO1)

Talking about an SSCI article he published as the sole author, ARCH1 explained why he had written it,

When I was in the US, I learnt that this journal is among the best few in our field, and it is extremely difficult to publish there. So when the opportunity presented itself (the journal was recruiting contributors among a group of archaeologists for a special issue), I grasped it right away. (ARCH1)

Speaking of a UK-based journal where he has successfully published three articles with his collaborators, ARCH2 said, "It is a century-old 'shop' most Western archaeologists regularly 'visit'. Its quality and standards are universally acknowledged."

Despite the overall small number of articles published in internationally-indexed journals by the participants, the quality and standard of (at least some of) these journals seem to have been well recognized. Even without the pressure from assessment systems, they consciously reached for higher standards and opted to publish in these journals. In this sense, such indexes as the SSCI and A\&HCI or the journals indexed by them have been given the symbolic meaning of high quality, rigorous standards and even trustworthiness.

Thirdly, even more participants (ECO2, ECO3, SOC2 and $\mathrm{ARCH} 2)$ compared writing and bidding for publication in international journals to a learning process. In general, ECO3 believes that aiming at international journals is aiming at higher academic standards, which could boost the quality of research and is particularly beneficial for younger researchers.

Indeed, ECO2 felt that she had benefited a lot from working with her NES collaborator, reviewers and journal editors at least in terms of English language and academic thinking. That is also one of the reasons explaining why "writing in English is time-consuming, but I am still willing to do it" (ECO2). According to ECO2,

My collaborator helped me revise my parts of the manuscript, and the changes she made were so brilliant! With a one-word change, the whole sentence could take on a new look! Such learning experience cannot be gained through any other means... And the editor I worked with on that article is in the area of China studies himself, and he knows China well. I read through all his comments, and have learnt so much from them! (ECO2)

In a similar vein, both $\mathrm{SOC} 2$ and $\mathrm{ARCH} 2$ noted how they were impressed by the methodical and meticulous manner of these journals in dealing with submissions. Half-jokingly, SOC2 confided,

These journals treat your submissions seriously. Even if your article was "killed", they would give you some pertinent comments to let you know why. For submissions to domestic journals, in most cases, I have no idea why my articles were "killed"; not to mention the long waiting time before someone informs you of that. In this sense, submitting to international journals at least enables me to learn something from their comments! (SOC2) 
On the ground of recognizing the general high standards of international journals, the participants above viewed the process of writing and bidding for publication there as a learning process. Apart from enhancing language skills and academic thinking, as in the case of ECO2, the rigorous, standardized or professionalized operation of the journals was mentioned. Either consciously or unconsciously, comparison between Chinese and international journals were made - the account of SOC2 indicates that despite the substantial progress made by Chinese journals in terms of academic rigor and standardization in the past years [12], perceivable gaps still exist between the two.

Fourthly, a rather alternative response came from SOC3, who aspires to the intellectual atmosphere of Western academia, and enjoys communicating with Western academics. As indicated by him, the "intellectual atmosphere" consists of at least the tolerance of different viewpoints, rigorous academic standards and a deep-rooted tradition of scientific inquiry, some of which are manifested in international journals. As shared by SOC3,

If I can foresee that an article will not possibly be accepted by and published in domestic journals, I will compose it in English and submit it to international journals. It is mainly because of ideological problems; domestic journals are still quite strict in this aspect. (SOC3)

This strategy adopted by SOC3 in his writing and publishing practices can be viewed as an illustration of the "tolerance of different viewpoints". In this sense, international journals seem to have provided a forum for scholars to voice different viewpoints and to publish alternative research outside of domestic journals.

\subsubsection{Issues and Concerns Related to Publishing in English-Medium International Journals}

Other than the merits and the benefits, several issues and concerns seem to have resulted in a lack of enthusiasm in English-medium international publishing among some participants. Yet, conflicting viewpoints and different practices were also reported by other participants.

Firstly, if Chinese and Western academia can be viewed as separate discourse communities [11] (p. 9), the nine participants have oriented themselves differently to these communities, which in turn have influenced their voluntary investment in participating in their practices. Among all participants, ECO3 and ARCH3 have most firmly and explicitly oriented themselves towards the local or domestic community. ECO3 shared his thoughts,

From my own perspective, I do not have the least intention to submit to international journals.

All my English publications were written at the invitation of editors and friends. If not for the sake of "giving face", I would not have written them, because my research aims primarily at domestic audience. I do not really care about turning it into English. (ECO3)

According to $\mathrm{ARCH} 3$, he does not care about the potentially larger impact or higher visibility of international publications either, because, among other reasons,

You are not in that "circle" (Western academia), and are not working under their requirements.

What you are concerned with are the thoughts of the people around you; and the people around you do not read those journals. (ARCH3)

As a matter of fact, both ECO3 and ARCH3 have a good command of English, and both have a number of English publications, either indexed or non-indexed; but rarely have they taken the initiative to write and submit English articles for international publication. In the case of ECO3, his English 
publications were mostly written at the invitation of editors; and in the case of ARCH3, they were mostly written by his NES collaborators. In other words, the voluntary investment into English writing and publishing from both ECO3 and ARCH3 was minimal, which is in line with their orientations.

Different from ECO3 and $\mathrm{ARCH} 3$, all the other participants of this study, especially some of the younger scholars (ECO2, SOC2 and SOC3), have exhibited certain degrees of alignment with Western academia and their practices, although the main focus of their attention is still on the domestic community or Chinese academia. The accounts provided by ECO2, SOC2 and SOC3, as reported throughout Sections 3.1 and 3.2, help demonstrate how their alignments are consistent with their voluntary investment.

Secondly, the three factors of the tremendous investment, the worthiness of the investment and the less-than-favorable assessment schemes were found to be intertwined and become a major source of conflicts for several participants. Specifically, participants in general reported two- to ten-fold investment of time and effort in writing an English article as compared to a Chinese one of similar length. Under this circumstance, the value of such publications, and that if they are worthy of the investment, has often been questioned. On another front, even if the internationally-indexed journals have been included in the assessment schemes, and viewed as equal to top-tier domestic journals, from a pragmatic perspective, it does not constitute effective incentive or even "just treatment" when the tremendous investment is considered. ECO1, ECO3 and ARCH1 seem to have shown greater concerns over these conflicts, but not ECO2, SOC2 and SOC3.

In the case of ARCH1, even after more than ten years' academic training in the US, he still finds writing academic English in his field demanding. The predicament caused by the vast investment, the unfavorable assessment scheme and his own inclination to make contribution to prestigious journals can be observed from his account below,

It usually takes me at least three months to compose an English article, and that is under the precondition that I have formulated my viewpoints in advance and I have had some Chinese writing to build upon. To start anew, a whole year can hardly be enough. For a Chinese article of the same length, to start from zero, I need only three weeks. But then again, why did I spend so much time to write that English article? Because the editor invited it from me. Otherwise, I would not have done that. It is a waste of time! Though I do not have the pressure to publish in English, I am pressured to publish in Chinese. If I do not have a decent number of Chinese publications for annual assessment, I would be embarrassed! (ARCH1)

For ECO1, although "getting published internationally is desirable", under the current assessment scheme, he chose to be "pragmatic",

There have to be requirements, some requirements entailing international publications, only then will I do it. As for myself, what is the point of investing two- to three-fold time and effort in writing an English article (when I can write a Chinese one with ease)? (ECO1)

ECO3, who doubled as researcher and director of his institute, is also keenly aware of the tremendous investment involved in getting published internationally. Being most concerned with its "worthiness", he stated his viewpoint,

We would not oppose such practices (bidding for publication in international journals); but we would not encourage it either. The lengthy process from composing, revising to finalizing the 
manuscript could well be used to do more domestic research, and we have plenty of that waiting to be done. (ECO3)

Interestingly, in face of the same conflicts, three younger academics expressed very different viewpoints. As stated by ECO2, SOC2 and SOC3,

I think I will write more in English in future; I would say it is meaningful. It is not out of the consideration of monetary income, needless to say that there is none. It is from the perspective of doing the job. You find an issue interesting and feel the obligation to write about it. (ECO2)

I will write more in English than Chinese in future, as long as the required workload is fulfilled. You have to think about, regardless of academic ranks or assessment, that English is playing a hegemonic role now. To compete for discourse power in an area, you have to use English to make yourself heard! (SOC2)

Assessment and rewarding schemes do not have much influence on me; and I believe they can only become more favorable to English writing in future. That way, I will write even more in English. This is the general trend-the increasing number of returnees will bring in new competition mechanism and English publications will definitely be part of it. I have to get prepared from early on. (SOC3)

From the accounts of the first three participants, the conflicts between the three factors can be well observed. This is consistent with the findings from the study of Flowerdew and $\mathrm{Li}$ [11], and in a sense is also applicable to many other NNES researchers. However, the three younger participants showed much less concerns over the constraints caused by the conflicting factors, and they seem to be determined to continue with their English writing endeavors and are confident in the value of doing so.

Thirdly, ECO3, SOC1 and ARCH1 also made some critical comments in relation to international journals' values and orientations, about which SOC3 had some differing thoughts. Both ECO3 and ARCH1 noted that they do not always share the values of international journals and sometimes find their orientations questionable. From his own experiences, ECO3 found that "English journals usually pay more attention to 'form' than 'content'; they do not really care about the research findings and conclusions".

$\mathrm{ARCH} 1$ found that some top-ranking English journals in archaeology show a preference for "eyecatching" research or findings over those with true academic value.

Regarding this issue, SOC1 provided an account of an incident happened in her institute,

We once had a young colleague applying for higher academic ranks with two articles published in top-tier SSCI journals. He failed because the academic board deemed that the articles do not contain much innovative work - the research is rather "basic" from the perspective of domestic academics; it was accepted by international journals just because Western academia knew too little about the research in China. (SOC1)

Conversely, SOC3 opposed the practice of "double-checking" the value of international publications and shared his thoughts,

Some people say that the articles published abroad do not have much value. This is actually a prevailing viewpoint. I guess this is a case of "sour grape". Simply because they are not capable of doing it, they downplay it. They know nothing about the arduous process (of writing and getting published)... They also have to admit that even the best journals in China are no comparison to international journals in terms of their standardized, rigorous and law-abiding 
operation. I agree that some articles published abroad are of mediocre or even poor quality, but so are those published in Chinese journals! (SOC3)

Previous researchers have pointed out that "the varied ideologies, paradigms and discourses" in the HSS research prevent it from being homogenized by one single language and one set of academic standards [31] (p. 49, citing Altbach, 1998). Indeed, in face of the potential hegemony of "center" standards, considerable resistance from the HSS academics were observed in prior studies (e.g., $[4,8,11]$ ) as well as the present one. However, SOC3 in this study seems to represent another type of resistance. When the standard and values of international journals were questioned and negated, he resisted such questioning and negation and emphasized their merits over their drawbacks.

Fourthly, another concern came from the belief that writing in a second language would almost inevitably reduce the level of precision and accurateness that writing in a first language could afford, and in consequence undermine and downgrade the quality of the presentation of the research being reported. In such disciplines as archaeology, this issue seems to be particularly prominent; whereas in economics and sociology the problem is less severe. ARCH3 felt quite strong about this point and commented,

I believe most people, even if they have obtained their PhD degrees in Anglophone countries, cannot use English with the same facility as Chinese. To write about Chinese history, archaeology and philosophy in English is even more challenging. The mere task of expressing yourself clearly is hard. (ARCH3)

ARCH3's viewpoint was echoed by ARCH1, whose strenuous effort in writing English articles despite his prolonged overseas experience was reported earlier,

Academic writing in the HSS is all about language and expressions. But when you are writing in English, your language use can never be the same as NES researchers; you are an NNES researcher after all. (ARCH1)

Surprisingly, viewpoints shared by ECO3 and SOC3 are quite the opposite. ECO3, the most prolific English writer of all participants in terms of the absolute number of international publications, made the following comments,

Economic writing does not require much embellishment; for academic papers, the most simple and direct expressions would be enough. Language is only the packaging of the research. (ECO3) SOC3 made the following remarks on the English writing in his area,

Academic writing in my area is different from, say, anthropology or more theoretical writing. If we deal with a problem in China studies, and report empirical research, the requirements on language are not very high. Compared to literary studies, ethnology or anthropology, they are actually much lower. (SOC3)

The viewpoint voiced by $\mathrm{ARCH} 3$ and $\mathrm{ARCH} 1$ coincides with de Swaan [32], who made the point that the HSS disciplines are heavily language-bounded, and depend their knowledge production and dissemination on the accurate and proficient use of descriptive language, and thus their Anglicization poses greater challenges to the academics who use English as a second or additional language. The accounts of ECO3 and SOC3, however, do not seem to be consistent with that. Obviously, within the broad and general categorization of the HSS, writing conventions and requirements on language can vary drastically across (sub)disciplines. 


\section{Discussion}

In the previous sections, research findings were reported to address the two research questions. First, participants' initial experiences of writing and publishing in internationally-indexed journals and the circumstances under which they wrote their internationally-indexed articles. Second, their attitudes towards writing and publishing in internationally-indexed journals as developed in their practices.

Regarding the first research question, unlike many academics from S\&T disciplines, whose initial experiences of international publication (in English) could be dated back to their master or PhD years, often as a graduation requirement [33], most participants of this study started to write and publish in English only after their formal academic career began. Moreover, nearly all their initial experiences in this aspect were closely associated with their overseas education or cross-border academic exchanges, as some of the resources and opportunities afforded by the process of globalization [15]. These experiences oftentimes put the participants into contact with their NES collaborators/mentors, trained them in the skills necessary for writing and publishing in English, and instilled into them an awareness of the importance of such practices or an inclination to identify themselves with the orientation and values of Western academia.

Being the "top-performers" in terms of English writing and publishing in the context of CASS, the nine participants from economics, sociology and archaeology had published 70 SSCI and A\&HCI articles before this study was conducted. In most cases, the participants played a fairly passive role in their writing instead of an active one. That is to say, the articles were mostly written at the suggestion of NES scholars (ECO1, ECO2, SOC1 and SOC2) or at the invitation of journal editors (ECO2, ECO3 and ARCH1). Seldom did the participants take the initiative to propose collaboration, or to write and bid for publication (SOC2, SOC3 and ARCH2). What's more, as shown in Section 2.3, less than half (30/70) of these articles were first-authored by one of the participants, indicating the largely supporting role, instead of a leading one, played by them in these articles. Both facts confirmed that English writing and publishing is still far from being the institutionalized practice in these disciplinary areas, at least at the CASS.

Regarding the second research question, the high visibility (ECO2, SOC2 and ARCH2), rigorous standard (ECO1, ARCH1 and $\mathrm{ARCH} 2)$ and diversified orientations (SOC3) of international journals as well as the learning opportunities submitting to these journals affords (ECO2, ECO3, SOC2 and ARCH2) received positive remarks from the participants. To relate these comments with participants' previous practices and future plans, it can be observed that: 1) younger scholars and those who have prolonged overseas experience tend to be more enthusiastic about English writing and publishing, and they are also more optimistic about overcoming the disadvantages they might have to endure as NNES researchers; 2) participants' attitudes towards English writing and publishing seem to align with the amount of voluntary investment they have put and will continue to put in it.

Other than the positive remarks, issues of concern and realistic constraints were also reported by the participants. These deterring factors have often prevented the participants from investing more time and effort in English writing and publishing despite the resources and opportunities they might possess, for instance, high English proficiency level and opportunities to publish in prestigious journals. The most prominent of these factors include participants' self-orientation towards local communities (ECO3 and ARCH3); the conflicts between the tremendous investment involved in English writing and 
publishing, the dubious value of such publications and the limited recognition accorded to them in assessment and rewarding schemes (ARCH1, ECO1 and ECO3); the "questionable" values and orientations of some international journals (ECO3, SOC1 and $\mathrm{ARCH} 1$ ); and the potential detriments writing in a second language may bring to the presentation of the research reported (ARCH1 and ARCH3).

From their research carried out in the context of higher education, Flowerdew and Li [11] (p. 13) drew the conclusion that "English is still far from becoming the preferred language of research and publication for Chinese HSS scholars and that this is likely to remain the case for some years to come". The findings of the present study, conducted at a central research institution with a small sample of participants, echo their viewpoint. Nevertheless, two issues emerged from the study are worth a mention.

Firstly, it is interesting to notice the distinction made between international publications for the purposes of "going-out" and "disseminating new research", either explicitly or implicitly mentioned by several participants. The "going-out" type of publications, often based on existing research previously released in Chinese, were usually written to fill the gaps in Western academia's understanding of Chinese research, and are more common among the participants. They are also consistent with the new national research policy encouraging the exportation of Chinese culture and Chinese HSS research [12]. Comparatively, international journals were used much less by the participants as the venues to disseminate original research. Presumably, it was caused by the facts that such writing is more challenging; and that Chinese academia and Western academia are still separate discourse communities with differing values, orientations and paradigms. Such practices are clearly different from those in the S\&T, where scholars tend to announce their original and cutting-edge research in internationally-indexed journals to the extent that large amounts of high-quality research in the academic "periphery" outflow to the "center" [34].

Secondly, despite the marginal position of English writing and publishing in the HSS now, different forces may bring about changes in practices in due time. Currently, noticeable tensions and conflicts can be observed from even the small number of participants of the present study, especially among the younger scholars and returnees. For instance, younger scholars like SOC3 defended the quality and standard of "center" journals out of their own perceptions and alignment regardless of the many questioning voices. Returnees like ARCH1 were stuck in the dilemma of working mainly in the local community and adhering to local practices, but also trying to make contributions to a distant community that they also identified with, a situation similar to the one observed by Casanave [35] from four Japanese academics returning from the West. Even though local forces influence academics' writing practices more heavily than larger disciplinary and historical forces, as argued by Casanave, it is expected that the increasing global exchanges and the rising number of returnees entering academia will bear on local practices and policies progressively.

\section{Conclusions}

This study, by and large, confirmed the marginal position English writing and publishing takes in the research work of the academics interviewed, even if they are the "top-performers" among their peers in this aspect. Currently, the majority of their international publications were produced passively 
and for the purpose of "going-out" only. Both merits and potential problems involved in such practices were reported. Although these problems have prevented some participants from investing more time and effort in English writing, younger participants and those with extensive overseas experience seem to be able to see greater value in publishing internationally, and they are also more positive and enthusiastic about such practices.

Findings from this study carry implications for institutional administrators and HSS researchers from both higher education and academic research institutes. For institutional administrators, more favorable micro policies need to be formulated and implemented if international publications are to be encouraged from HSS researchers. Nonetheless, caution has to be taken to avoid overemphasizing center-based indexes so as to do harm to Chinese scholarship. For HSS researchers who aim at getting published internationally but do not possess sufficient resources, especially in terms of the appropriate English writing skills, collaborating with NES scholars seems to be a feasible compensatory measure. In addition, more opportunities for exchanges, collaboration and disciplinary-specific training in academic writing need to be created for HSS researchers at different levels. Nonetheless, caution has to be taken to avoid overemphasizing the role of English so as to ignore the quality of research.

On a final note, future research can be focused on more in-depth investigations into the writing and publishing practices of individual HSS academics or within individual HSS disciplines. Research collaboration between Chinese researchers and their NES counterparts, as almost all participants of this study have engaged in, can also be a potentially interesting research area to explore.

\section{Acknowledgments}

I gratefully acknowledge the valuable comments provided by my supervisor Dr Yongyan Li and the constructive feedback from the two Publications reviewers on earlier versions of this paper. Any problems, however, remain my own. Special thanks are due to my research participants for generously sharing their thoughts and experiences with me.

\section{Conflicts of Interest}

The author declares no conflict of interest.

\section{References}

1. Gotti, M. Variation in academic texts. In Academic Identity Traits : A Corpus-Based Investigation, Gotti, M., Ed.; Peter Lang: Bern, Switzerland; New York, NY, USA, 2012; pp. 23-42.

2. Ammon, U. The Dominance of English as a Language of Science: Effects on Other Languages and Language Communities; Mouton de Gruyter: Hawthorne, NY, USA, 2001.

3. Canagarajah, A.S. A Geopolitics of Academic Writing; University of Pittsburgh Press: Pittsburgh, PA, USA, 2002.

4. Lillis, T.; Curry, M.J. Academic Writing in a Global Context: The Politics and Practices of Publishing in English; Routledge: Abingdon, UK; New York, NY, USA, 2010. 
5. Duszak, A.; Lewkowicz, J. Publishing academic texts in English: A Polish perspective. J. Engl. Academic Purposes 2008, 7, 108-120.

6. Li, Y. A doctoral student of physics writing for publication: A sociopolitically-oriented case study. Engl. Specif. Purposes 2006, 25, 456-478.

7. Uzuner, S. Multilingual scholars' participation in core/global academic communities: A literature review. J. Engl. Academic Purposes 2008, 7, 250-263.

8. Li, Y.; Flowerdew, J. International engagement versus local commitment: Hong Kong academics in the humanities and social sciences writing for publication. J. Engl. Academic Purposes 2009, 8, 279-293.

9. Chien, S.-C. Writing for scholarly publication in English for researchers in the field of arts and humanities in higher education in Taiwan. Available online: http://140.127.82.166/retrieve/18967/15.pdf (accessed on 12 February 2015),

10. Chou, C.P.; Lin, H.F.; Chiu, Y.-j. The impact of SSCI and SCI on Taiwan's academy: An outcry for fair play. Asia Pacific Education Rev. 2013, 14, 23-31.

11. Flowerdew, J.; Li, Y. English or Chinese? The trade-off between local and international publication among Chinese academics in the humanities and social sciences. J Second Lang. Writ. 2009, 18, 1-16.

12. Feng, H.; Beckett, G.; Huang, D. From "import" to "import-export" oriented internationalization: The impact of national policy on scholarly publication in China. Lang. Policy 2013, 12, 251-272.

13. ISTIC. Statistical Data of Chinese S\&T Papers (2013); Institute of Scientific and Technical Information of China: Beijing, China, 2013.

14. He, X.; Xu, S. Jianguo yilai woguo renwen shehui kexue xueshu yanjiu guojihua fazhan niandai fenxi - Jiyu SSCI, A\&HCI (1956-2006) de dingliang fenxi [Diachronic changes in the internationalized academic research in the humanities and social sciences of China since 1949 - A quantitative analysis based on SSCI and A\&HCI (1956-2006)]. Shandong Shehui Kexue [Shandong Social Sciences] 2008, 2008, 141-144.

15. Steger, M.B. Globalization : A Very Short Introduction; Oxford University Press: New York, NY, USA, 2003.

16. Shi, L. Writing in two cultures: Chinese professors return from the West. Canadian Modern Language Review 2003, 59, 369-391.

17. Li, L.; Hua, W. Zouxiang shijie de zhongguo gaoxiao renwen sheke yanjiu zhong de guojia hezuo shikuang fenxi [International cooperation analysis of Chinese academic research in the humanities and social sciences in world core journals by Chinese university faculty]. Zhongguo Gaojiao Yanjiu [China Higher Education Research] 2011, 2011, 15-18.

18. Flowerdew, J.; Li, Y. The globalization of scholarship: Studying Chinese scholars writing for international publication. In Writing in Foreign Language Contexts : Learning, Teaching, and Research, Manchón; R., Ed.; Multilingual Matters: Bristol, UK; Buffalo, NY, USA, 2009; pp. $156-182$.

19. Jin, C. "Zouchuqu" zhanlve shinian huigu: Chengiiu yu tiaozhan [A retrospect of the ten years of "going-out": Accomplishments and challenges]. Xiandai Guoji Guanxi [Contemporary International Relations] 2011, 2011, 2-4. 
20. He, X. Jianguo yilai woguo renwen shehui kexue xueshu yanjiu guojihua fazhan xueke fenxi Jiyu SSCI, A\&HCI (1956-2006) de dingliang fenxi [A disciplinary analysis of the internationalization of China's humanities and social sciences research since the founding of PRC - A quantitative analysis based on SSCI and A\&HCI (1956-2006)]. Dongyue Luncong [Dongyue Tribune] 2008, 29, 24-31.

21. He, X. Jianguo yilai dalu xueshu jigou renwen shehui kexue yanjiu guojihua xueshu chanchu dingliang fenxi - Jiyu SSCI, A\&HCI (1956-2006) de dingliang fenxi [The internationalized research output in the humanities and social sciences from mainland Chinese academic institutions since the founding of PRC - A quantitative analysis based on SSCI and A\&HCI (1956-2006)]. Qinghua Daxue Xuebao (Zhexue Shehui Kexue Ban) [Journal of Tsinghua University (Philosophy and Social Sciences Edition)] 2008, 23, 145-153.

22. Zheng, H. SSCI he A\&HCI shoulu zhongguo renwen shehui kexue hezhu lunwen tongji fenxi (1995-2004) [A statistical analysis of the co-authored articles by Chinese academics in the humanities and social sciences as indexed by SSCI and A\&HCI (1995-2004)]. Shehui Kexue Guanli yu Pinglun [Management and Review of Social Sciences] 2007, 2007, 47-55.

23. Jiang, X. Renwen sheke qingnian xuezhe guoji fawen de kunnan yu yingdui celve [Difficulties in international publication and coping strategies by young scholars in the humanities and social sciences]. Waiguo Yuwen [Foreign Language and Literature] 2014, 30, 101-106.

24. Sleeboom-Faulkner, M. The Chinese Academy of Social Sciences (CASS): Shaping the Reforms, Academia and China (1977-2003); Brill: Leiden, the Netherlands; Boston, MA, USA, 2007.

25. Ge, M. English writing for international publication in the age of globalization: Perceptions and practices of mainland Chinese academics in the humanities and social sciences. Course assignment, University of Hong Kong: Hong Kong, China, 2014.

26. Curry, M.J.; Lillis, T. Multilingual scholars and the imperative to publish in English: Negotiating interests, demands, and rewards. TESOL Quarterly 2004, 38, 663-688.

27. Prior, P.A. Tracing process: How texts come into being. In What Writing Does and How It Does It: An Introduction to Analyzing Texts and Textual Practices; Bazerman, C., Prior, P., Eds.; Lawrence Erlbaum: Mahwah, NJ, USA, 2004; pp. 167-200.

28. Merriam, S.B. Qualitative Research: A Guide to Design and Implementation; John Wiley \& Sons: San Francisco, CA, USA, 2009.

29. Hatch, J.A. Doing Qualitative Research in Education Settings; SUNY Press: Albany, NY, USA, 2002.

30. Yin, R.K. Case Study Research: Design and Methods, 4th ed.; Sage Publications: Thousand Oaks, CA, USA, 2009.

31. Yang, R. Indigenised while internationalised? Tensions and dilemmas in China's modern transformation of social sciences in an age of globalisation. In Spatial Social Thought: Local Knowledge in Global Science Encounters; Kuhn, M., Okamoto, K., Eds.; ibidem-Verlag: Stuttgart, Germany, 2013; pp. 43-61.

32. de Swaan, A. English in the social sciences. In The Dominance of English as a Language of Science : Effects on Other Languages and Language Communities; Ammon, U., Ed.; Mouton de Gruyter: Hawthorne, NY, USA, 2001; pp. 71-83. 
33. Li, Y. Apprentice scholarly writing in a community of practice: An intraview of an NNES graduate student writing a research article. TESOL Quarterly 2007, 41, 55-79.

34. Salager-Meyer, F. Scientific publishing in developing countries: Challenges for the future. $J$. Engl. Academic Purposes 2008, 7, 121-132.

35. Casanave, C.P. Transitions: The balancing act of bilingual academics. J. Second Lang. Writ. 1998, 7, 175-203.

(C) 2015 by the author; licensee MDPI, Basel, Switzerland. This article is an open access article distributed under the terms and conditions of the Creative Commons Attribution license (http://creativecommons.org/licenses/by/4.0/). 